\title{
FORMAÇÃO DE MUDAS DE PESSEGUEIRO CV. AURORA-1 ENXERTADAS EM DOIS CLONES DE UMEZEIRO (Prunus mume Sieb. et Zucc.) PROPAGADOS POR ESTACAS HERBÁCEAS ${ }^{1}$
}

\author{
FERNANDO MENDES PEREIRA² \& NEWTON ALEX MAYER ${ }^{3}$
}

\begin{abstract}
RESUMO - O presente trabalho teve por objetivo estudar a formação de mudas de pessegueiro 'Aurora-1' enxertadas nos Clones 10 e 15 de umezeiro (Prunus mume Sieb. et Zucc.) propagados por estacas herbáceas. Após o período de enraizamento, as estacas enraizadas foram transplantadas para sacos plásticos contendo substrato comercial e mantidas em viveiro com piso cimentado e coberto com sombrite (50\%), até que as hastes atingissem diâmetro em torno de $10 \mathrm{~mm}$. Neste estágio, os porta-enxertos foram enxertados com o pessegueiro cv. Aurora-1 pelo método da borbulhia por escudo modificado. Aos 135 dias após a enxertia, o experimento foi avaliado. Com os resultados obtidos, foi possível concluir que é viável a produção de mudas de pessegueiro 'Aurora-1' enxertadas nos Clones 10 e 15 de umezeiro propagados por estacas herbáceas, com índices de pegamento de enxerto em torno de $85 \%$ e mortalidade de porta-enxertos inferior a 7\%. O comprimento dos enxertos não é influenciado pelo clone de umezeiro utilizado como porta-enxerto, porém o diâmetro do enxerto é maior quando a enxertia é realizada no Clone 15.
\end{abstract}

Termos para indexação: Prunus persica (L.) Batsch, porta-enxerto, enxertia interespecífica, frutas de caroço.

\section{FORMATION OF 'AURORA-1' PEACH NURSERY PLANTS BUDDED ON TWO MUME'S CLONES (Prunus mume} Sieb. et Zucc.) PROPAGATED BY HERBACEOUS CUTTINGS

\begin{abstract}
The present study had for objective to study the formation of 'Aurora-1' peach nursery plants budded on Mume's Clones 10 and 15 propagated by herbaceous cuttings. After rooting period, the rooted cuttings were transplanted to plastic boxes containing commercial substrate and maintained under nursery conditions until the stems reached $10 \mathrm{~mm}$ diameter. In this period, the rootstocks were budded with 'Aurora-1'peach by modified ship bud. 135 days after the bud, the experiment was evaluated. From the obtained results, it was possible to conclude that the production of 'Aurora-1' peach budded on Mume's Clones 10 and 15 propagated by herbaceous cuttings is viable, with indexes of tissue union around $85 \%$ and rootstock mortality inferior to $7 \%$. The bud length is not influenced by Mume's clone used as rootstock, but the diameter of the buds is larger when the bud is accomplished in the Mume Clone 15.
\end{abstract}

Index terms: Prunus persica (L.) Batsch, rootstock, interspecific bud, stone fruits.

Uma das carências observadas na cultura do pessegueiro no Brasil é, sem dúvida, a necessidade de novas tecnologias na área de produção de mudas. Dentre essas necessidades, podem-se citar novas alternativas de porta-enxertos, métodos de propagação que garantam a manutenção das características genéticas da planta-matriz e o adequado estabelecimento no pomar, além de porta-enxertos ananizantes que possibilitem a redução dos espaçamentos entre plantas e linhas, tendência observada na moderna fruticultura (Pereira \& Mayer, 2005).

Diante da necessidade de se dispor de porta-enxertos compatíveis e que diminuam o vigor de pessegueiros e nectarineiras, o que pode permitir o adensamento dos pomares, foram iniciados na década de 80, no Instituto Agronômico de Campinas (IAC), estudos de enxertia e comportamento no campo utilizando o umezeiro (Prunus mume Sieb. et Zucc.) como porta-enxerto. Tais estudos foram bastante promissores e revelaram a compatibilidade da enxertia, aumentos na massa, teor de sólidos solúveis e porcentagem de vermelho na película dos frutos, além da redução no vigor das plantas e possibilidade de adensamento dos pomares (Campo Dall'Orto et al., 1992; Campo Dall'Orto et al., 1994).

A literatura apresenta relatos sobre a sanidade do umezeiro. Tzonev \& Yamaguchi (1999) citam a imunidade de trinta cultivares de umezeiro à podridão-parda-européia, causada por Monilinia laxa (Ehr.), e Smith (1925), citado por Layne (1974), identificou resistência do umezeiro à galha-bacteriana ou galha-de-coroa, causada por Agrobacterium tumefaciens (E.F.Sm. and Town.) Conn. Segundo Sherman \& Lyrene (1983), o umezeiro apresenta resistência a nematóidesde-galha, o que foi comprovado por Rossi et al. (2002) para Meloidogyne incognita Raça 2 e M. javanica, características estas de grande importância para a seleção de um porta-enxerto.

Em condições de viveiro, a compatibilidade da enxertia do umezeiro com nove cultivares de pessegueiro e duas de nectarineira e a redução da altura das mudas também foram comprovadas (Nakamura et al., 1999). Entretanto, os estudos de compatibilidade e desenvolvimento no campo, realizados no IAC, revelaram grande variabilidade genética das sementes do umezeiro, o que resultaram em plantas com acentuadas diferenças de vigor no campo, sugerindo a necessidade de propagação clonal.

A partir de 1998, iniciaram-se na Faculdade de Ciências Agrárias e Veterinárias (FCAV), Universidade Estadual Paulista (UNESP), Câmpus de Jaboticabal-SP, estudos com a propagação do umezeiro por estacas herbáceas, onde se verificou a viabilidade do método (Nachtigal et al., 1999; Mayer et al., 2001; Mayer et al., 2002; Mayer \& Pereira, 2003; Mayer \& Pereira, 2004a). Em estudos de reação a fitonematóides, constatou-se que os Clones $05 ; 10$ e 15 de umezeiro apresentam resistência a Meloidogyne javanica (Mayer et al., 2003). Entretanto, faz-se necessário estudos de enxertia com pessegueiro em condições de viveiro, para que esta nova tecnologia possa constituir uma alternativa para solucionar alguns problemas da cultura do pessegueiro, especialmente no que diz respeito à produção de mudas com qualidade.

O presente estudo teve por objetivo estudar a formação de mudas de pessegueiro cv. Aurora-1 enxertadas em dois clones de umezeiro (Prunus mume Sieb. et Zucc.) propagados por estacas herbáceas.

A partir de plantas de umezeiro dos Clones 10 e 15, material selecionado na Faculdade de Ciências Agrárias e Veterinárias, Câmpus de Jaboticabal-SP (FCAV/UNESP), quanto à capacidade de enraizamento (Nachtigal et al., 1999; Mayer et al., 2001, Mayer et al., 2002, Mayer \& Pereira, 2003, Mayer \& Pereira, 2004a), foram obtidas estacas herbáceas com $12 \mathrm{~cm}$ de comprimento, tratadas com solução hidroalcoólica de ácido indolbutírico a 2.000mg. $\mathrm{L}^{-1}$, por cinco segundos (Mayer et al., 2001), e enraizadas em câmara de nebulização intermitente, localizada no "Sítio

\footnotetext{
${ }^{1}$ (Trabalho 051/2005). Recebido: 04/04/2005. Aceito para publicação: 01/08/2005. Apoio Financeiro: FAPESP. Parte da Tese de Doutorado do segundo autor.

${ }^{2}$ Eng. Agr., Dr., Prof. Voluntário do Departamento de Produção Vegetal da Faculdade de Ciências Agrárias e Veterinárias (FCAV), Universidade Estadual Paulista (UNESP). Via de Acesso Prof. Paulo Donato Castellane s/n, CEP 14884-900, Jaboticabal-SP. E-mail: fmendes@fcav.unesp.br.

${ }^{3}$ Eng. Agr., Dr., Aluno do Curso de Pós-doutorado em Agronomia da Faculdade de Ciências Agrárias e Veterinárias (FCAV), Universidade Estadual Paulista (UNESP), Câmpus de Jaboticabal-SP. E-mail: mayersul@yahoo.com.br.
} 
São João", em Taquaritinga-SP, do final de agosto ao final de outubro de 2001. Após o período de enraizamento, as estacas enraizadas foram selecionadas, objetivando eliminar as que apresentavam inadequada quantidade e distribuição das raízes ao redor da estaca. As estacas selecionadas foram transplantadas para sacos plásticos perfurados (28 x $18 \mathrm{~cm}$ ), contendo substrato comercial, constituído de uma mistura de cascas processadas e enriquecidas, vermiculita expandida e carvão vegetal granulado, com $150 \%$ de capacidade de retenção de água.

A fertilização do substrato consistiu de uma adubação com Osmocote $^{\circledR}(\mathrm{N}=15 \% ; \mathrm{P}=10 \% ; \mathrm{K}=10 \% ; \mathrm{Ca}=3,5 \% ; \mathrm{Mg}=1,5 \% ; \mathrm{S}=3,0 \%+$ micronutrientes), na dose de $6 \mathrm{~g}$ por saco plástico, aos 19 dias após o transplantio, cujo tempo de liberação é de 5 a 6 meses. Realizou-se também uma aplicação de calcário dolomítico (137\% de PRNT; 45\% de $\mathrm{CaO}$ e $25 \%$ de $\mathrm{MgO}$ ), na dose de 4 a 5 g por saco plástico, aos 90 dias após o transplantio, objetivando suprir as necessidades de cálcio e magnésio.

Os porta-enxertos, Clones 10 e 15 de umezeiro, foram mantidos em viveiro de piso cimentado e coberto com sombrite $(50 \%$ de sombreamento), até atingirem diâmetro em torno de $10 \mathrm{~mm}$, considerados ideais para a execução da enxertia (Campo Dall'Orto et al., 1992; Nakamura et al., 1999). Para a enxertia, coletaram-se ramos borbulheiros do pessegueiro 'Aurora-1' em pomar comercial, localizado em TaiaçuSP. A escolha desta cultivar foi baseada nos melhores resultados de pesquisa obtidos com o pessegueiro após 15 anos, na região de Jaboticabal-SP (Pereira et al., 2002). As folhas dos ramos borbulheiros foram retiradas com o pecíolo, a fim de facilitar o amarrio com a fita plástica. Adotou-se a enxertia de borbulhia por escudo modificada, que consistiu da realização de um único corte descendente no porta-enxerto, sem encaixe (em forma de lasca), e amarrio da borbulha, cobrindo-se totalmente a gema. Dessa forma, a fixação da borbulha ao porta-enxerto foi feita somente com a fita plástica, de adequada elasticidade. Para o amarrio, cobriu-se inicialmente a gema com cuidado para não danificála e, em seguida, esticando-se a fita, toda a área de união das partes. Aos 34 dias após a enxertia, as fitas plásticas foram retiradas com uma lâmina de barbear, momento em que também foi realizada uma poda dos porta-enxertos a $20-25 \mathrm{~cm}$ acima do ponto de enxertia, objetivando "forçar" a brotação do enxerto. Aos 70 dias após a enxertia, foi feita a eliminação total das copas dos porta-enxertos, cortando-as logo acima do enxerto com uma tesoura de poda.

$\mathrm{O}$ experimento foi conduzido em delineamento inteiramente casualizado, com 2 tratamentos (Clones 10 e 15) de 10 repetições, sendo que cada parcela foi constituída de 09 plantas. No dia 14 de outubro de 2003 (135 dias após a enxertia), avaliaram-se as variáveis porcentagem de pegamento de enxerto, mortalidade dos porta-enxertos, comprimento de enxerto (avaliado com fita métrica) e diâmetro do enxerto a $5 \mathrm{~cm}$ acima do ponto de enxertia (avaliado com paquímetro digital). Os dados originais da variável porcentagem de pegamento de enxerto foram transformados para Arco-Seno $\sqrt{P / 100}$. Os dados foram submetidos à análise de variância pelo teste $\mathrm{F}$ e as médias comparadas pelo teste de Tukey, ao nível de $5 \%$ de probabilidade.

De acordo com os resultados obtidos (Tabela 1), não foi detectada diferença estatística na porcentagem de pegamento de enxerto entre os Clones 10 e 15. Em ambos os clones estudados, os valores de
$84,45 \%$ (Clone 10) e 86,03\% (Clone 15) foram considerados satisfatórios e superiores aos obtidos com porta-enxertos de menor diâmetro, em torno de $4 \mathrm{~mm}$ (Mayer et al., 2005), onde foram obtidas porcentagens que variaram de 51,0 a $71,0 \%$ de pegamento de enxertos. No presente estudo, a mortalidade de porta-enxertos em algumas parcelas foi de $0 \%$, com valor médio entre as parcelas inferior a 7\%, razão pela qual esta variável não pode ser analisada estatisticamente. Foi possível observar que, em porta-enxertos de umezeiro com diâmetro em torno de $10 \mathrm{~mm}$, a lesão provocada para a realização da enxertia não interfere no crescimento normal das plantas. Esta constatação revela claramente a necessidade de se dispor de porta-enxertos com satisfatório desenvolvimento e diâmetro adequado para a realização da enxertia (em torno de 8 a $12 \mathrm{~mm}$ ), para que porcentagens satisfatórias de pegamento de enxerto possam ser obtidas.

Não foram encontrados quaisquer sintomas de incompatibilidade entre o enxerto e o porta-enxerto, o que comprova relatos da literatura sobre a viabilidade técnica do uso do umezeiro como porta-enxerto para pessegueiro (Campo Dall'Orto et al., 1992; Nakamura et al., 1999). De acordo com Hartmann \& Kester (1978), não há regra definida para o sucesso na enxertia interespecífica. Quanto mais botanicamente afins, maiores as probabilidades de êxito. Entretanto, esses autores destacam que isso não se realiza de modo consistente, visto que as classificações botânicas se baseiam nas características reprodutivas, e o enxerto envolve principalmente propriedades vegetativas das plantas.

Em trabalhos já realizados com enxertia de cultivares de pessegueiro e nectarineira em umezeiro (Campo Dall'Orto et al., 1992; Nakamura et al., 1999), as porcentagens de pegamento de enxerto foram sempre superiores a $70 \%$. Nestes trabalhos, os porta-enxertos encontravam-se com aproximadamente $10 \mathrm{~mm}$ de diâmetro e $1 \mathrm{~m}$ de altura, no momento da enxertia. Após três anos de avaliações no campo, utilizando a seleção de umezeiro 'Iacume', Campo Dall'Orto et al. (1992) verificaram que a 'Aurora-1' foi uma das cultivares que apresentou melhor comportamento em termos de uniformidade de plantas, compatibilidade da enxertia, maior equilíbrio da frutificação/vegetação e do número de frutos produzidos, sendo também observadas reduções de $2 / 3$ a $1 / 2$ no porte das plantas, em relação às plantas enxertadas em 'Okinawa'.

Não foi encontrada diferença estatística entre os clones na variável comprimento de enxertos (Tabela 1), o que evidencia que, em condições de viveiro, os Clones 10 e 15 de umezeiro não influenciam no vigor da copa, mensurado através do comprimento do enxerto. Esta igualdade estatística também foi observada por Mayer et al. (2005), utilizando os mesmos clones e cultivar-copa. No presente estudo, os valores de comprimento de enxerto observados no Clone $10(52,86 \mathrm{~cm}) \mathrm{e}$ no Clone $15(56,12 \mathrm{~cm})$ evidenciam o rápido crescimento das mudas em apenas 135 dias após a enxertia, comprovando a compatibilidade do pessegueiro 'Aurora-1' com os clones de umezeiro na fase de viveiro, a viabilidade da metodologia de enxertia e do manejo utilizados. Também se destaca o adequado estabelecimento dos porta-enxertos propagados por estacas herbáceas nos sacos plásticos contendo substrato comercial, sendo esse outro avanço tecnológico na produção de mudas de pessegueiro com qualidade. Nakamura et al. (1999), utilizando portaenxertos de umezeiro propagados por sementes e substrato composto

TABELA 1 - Porcentagem de pegamento de enxertos, comprimento e diâmetro de enxertos do pessegueiro cv. Aurora-1 [Prunus persica (L.) Batsch] aos 135 dias após a enxertia, enxertado nos Clones 10 e 15 de umezeiro (Prunus mume Sieb. et Zucc.) propagados por estacas herbáceas. Taquaritinga-SP, outubro de 2003.

\begin{tabular}{cccc}
\hline Porta-enxerto & $\begin{array}{c}\text { \% de pegamento } \\
\text { de enxertos }\end{array}$ & $\begin{array}{c}\text { Comprimento de } \\
\text { enxertos (cm) }\end{array}$ & $\begin{array}{c}\text { Diâmetro a 5cm acima do } \\
\text { ponto de enxertia (mm) }\end{array}$ \\
\hline Clone 10 & 84,45 a & 52,86 a & $4,88 \mathrm{~b}$ \\
Clone 15 & 86,03 a & 56,12 a & 5,36 a \\
\hline F & $0,03^{\mathrm{NS}}$ & $3,60^{\mathrm{NS}}$ & $12,37^{* *}$ \\
\hline $\mathrm{CV}(\%)$ & 19,20 & 7,07 & 5,90 \\
\hline
\end{tabular}

** significativo ao nível de $1 \%$ de probabilidade; ${ }^{\text {NS }}$ não significativo. Médias seguidas por letras distintas, na mesma coluna, diferem entre si, pelo teste de Tukey, ao nível de 5\% de probabilidade. 
de uma mistura de terra, areia e esterco (3:1:1), observaram que a altura das mudas variou entre as diferentes cultivares-copa de pessegueiro estudadas, sendo os valores compreendidos entre 8,14 e $11,25 \mathrm{~cm}$, aos 150 dias após a enxertia.

Para o diâmetro do enxerto a $5 \mathrm{~cm}$ acima do ponto de enxertia (Tabela 1), observa-se que, no Clone 15, o diâmetro foi estatisticamente maior do que o observado no Clone 10. Essa informação indica um menor vigor do Clone 10, ainda na fase de viveiro. Entretanto, destacase que as mudas de pessegueiro formadas sobre ambos os clones de umezeiro demonstraram desenvolvimento adequado para o plantio definitivo no campo. De acordo com Nakamura et al. (1999), não foram encontradas diferenças no diâmetro do enxerto entre nove cultivares de pessegueiro e duas de nectarineira estudadas, quando enxertadas em "seedlings" de umezeiro, nem mesmo quando comparadas com as mudas enxertadas em 'Okinawa'.

Com as informações obtidas no presente trabalho, aliados à experiência adquirida com a propagação de clones de umezeiro por estacas herbáceas, transplantio para sacos plásticos contendo substrato comercial, estudos de crescimento na pré-enxertia (Mayer \& Pereira, 2004b) e comprovação da resistência a Meloidogyne javanica (Mayer et al., 2003), observa-se que o uso de clones de umezeiro, selecionados na FCAV/UNESP, como porta-enxerto para pessegueiro, apresenta promissoras perspectivas de sucesso. Os estudos estão sendo concluídos em condição de campo, onde sintomas de incompatibilidade não foram observados nos primeiros 24 meses.

Nas condições em que o presente trabalho foi conduzido, podese concluir que:

1. É viável a produção de mudas de pessegueiro cv. Aurora-1 enxertadas nos Clones 10 e 15 de umezeiro, apresentando índices de pegamento de enxerto em torno de $85 \%$ e mortalidade de porta-enxertos inferiores a $7 \%$.

2. O comprimento de enxertos não é influenciado pelo clone de umezeiro utilizado como porta-enxerto, porém o diâmetro do enxerto é maior quando a enxertia é realizada no Clone 15 de umezeiro.

\section{AGRADECIMENTOS}

À Fundação de Amparo à Pesquisa do Estado de São Paulo (FAPESP), pela concessão da bolsa de estudos e suporte financeiro.

Aos Srs. José Mauro da Silva e João Matheus da Silva, proprietários do "Sítio São João" (Taquaritinga-SP), pela colaboração na realização deste trabalho.

\section{REFERÊNCIAS}

CAMPO DALL'ORTO, F.A.; OJIMA, M.; BARBOSA, W.; MARTINS, F.P. O nanismo do pessegueiro induzido pela enxertia no damasqueiro-japonês. Pesquisa Agropecuária Brasileira, Brasília, v.27, n.3, p.517-521, 1992.

CAMPO DALL'ORTO, F.A.; BARBOSA, W.; OJIMA, M.; MARTINS, F.P.; FOBÉ, L.A. Comportamento de pessegueiros IAC enxertados no damasqueiro japonês e no pessegueiro 'Okinawa'. In: CONGRESSO BRASILEIRO DE FRUTICULTURA, 13., 1994, Salvador. Anais... Salvador: SBF, v.3, 1994. p.879-880.

HARTMANN, H.T.; KESTER, D.E. Propagación de plantas. 7. ed. México: Compañia Editorial Continental, 1978. 810p.
LAYNE, R.E.C. Breeding peach rootstocks for Canada and the Northern United States. HortScience, Alexandria, v.9, n.4, p.364-366, 1974.

MAYER, N.A.; PEREIRA, F.M.; NACHTIGAL, J.C. Propagação do umezeiro (Prunus mume Sieb \& Zucc.) por estaquia herbácea. Revista Brasileira de Fruticultura, Jaboticabal, v.23, n.3, p.673676, 2001.

MAYER, N.A.; PEREIRA, F.M.; NACHTIGAL, J.C. Efeito do comprimento de estacas herbáceas de dois clones de umezeiro (Prunus mume Sieb \& Zucc.) no enraizamento adventício. Revista Brasileira de Fruticultura, Jaboticabal, v.24, n.2, p.500-504, 2002.

MAYER, N.A.; PEREIRA, F.M. Enraizamento de estacas herbáceas de quatro clones de umezeiro (Prunus mume Sieb. et Zucc.) durante o inverno ameno, em Jaboticabal-SP. Revista Brasileira de Fruticultura, Jaboticabal, v.25, n.3, p.505-507, 2003.

MAYER, N.A.; PEREIRA, F.M.; SANTOS, J.M. dos. Reação de clones de umezeiro (Prunus mume Sieb. et Zucc.) e cultivares de pessegueiro a Meloidogyne javanica (Treub, 1885) Chitwood, 1949. Revista Brasileira de Fruticultura, Jaboticabal, v.25, n.1, p.181$183,2003$.

MAYER, N.A.; PEREIRA, F.M. Effect of wounds applied to the bases of herbaceous cuttings on the rooting of four japanese apricot clones (Prunus mume Sieb. et Zucc.) in an intermittent mist system. Acta Horticulturae, Wageningen, v.658, p.655-659, 2004a.

MAYER, N.A.; PEREIRA, F.M. Crescimento de três clones de umezeiro (Prunus mume Sieb. et Zucc.) e pessegueiro cv. Okinawa (Prunus persica (L.) Batsch.) propagados por estacas herbáceas. Revista Brasileira de Fruticultura, Jaboticabal, v.26, n.1, p.113-116, 2004b.

MAYER, N.A.; PEREIRA, F.M.; BARBOSA, J.C. Pegamento e crescimento inicial de enxertos do pessegueiro 'Aurora-1' em clones de umezeiro (Prunus mume Sieb. et Zucc.) e 'Okinawa' [Prunus persica (L.) Batsch] propagados por estacas herbáceas. Revista Brasileira de Fruticultura, Jaboticabal, v.27, n.1, p.102-106, 2005.

NACHTIGAL, J.C.; PEREIRA, F.M.; CAMPO DALL'ORTO, F.A.; OJIMA, M.; MARTINS, F.P. Propagação vegetativa do umezeiro (Prunus mume) por meio de estacas herbáceas. Revista Brasileira de Fruticultura, Jaboticabal, v.21, n.2, p.226-228, 1999.

NAKAMURA, C.H.; SCARPARE FILHO, J.A.; KLUGE, R.A. Avaliação preliminar do umezeiro como porta-enxerto para pessegueiro e nectarineira. Revista Brasileira de Fruticultura, Jaboticabal, v.21, n.2, p.116-118, 1999.

PEREIRA, F.M.; NACHTIGAL, J.C.; ROBERTO, S.R. Tecnologia para a cultura do pessegueiro em regiões tropicais e subtropicais. Jaboticabal: FUNEP, 2002. 62p.

PEREIRA, F.M.; MAYER, N.A. Pessegueiro: tecnologias para a produção de mudas. Jaboticabal: FUNEP, 2005. 65p.

ROSSI, C.E.; FERRAZ, L.C.C.B.; MONTALDI, P.T. Resistência de frutíferas de clima subtropical e temperado a Meloidogyne incognita raça 2 e M. javanica. Arquivos do Instituto Biológico, São Paulo, v.69, n.2, p.43-49, 2002.

SHERMAN, W.B.; LYRENE, P.M. Improvement of peach rootstock resistant to root-knot nematodes. Proceedings of the Florida State for Horticultural Society, Winter Haven, v.96, p.207-208, 1983.

TZONEV, R.; YAMAGUCHI, M. Resistance in some Prunus species in Japan against blossom blight, caused by Monilinia laxa (ehr.): Prunus armeniaca var. Ansu Maxim., Prunus armeniaca L., Prunus mume Sieb. et Zucc. and interspecific hybrids among Prunus species. Acta Horticulturae, The Hague, n.488, p.649-654, 1999. 